\title{
Optimization of Submerged Culture Conditions for Mycelial Growth and Extracellular Polysaccharide Production by Coriolus versiolor
}

Feifei Wang ${ }^{1,3}$, Jianchun Zhang ${ }^{1,2^{\star}}$, Limin $\mathrm{Hao}^{1,2^{\star}}$, Shiru $\mathrm{Jia}^{3}$, Jianming $\mathrm{Ba}^{4}$ and Shuang $\mathrm{Niu}^{1,3}$

${ }^{1}$ The Research Center of China Hemp Materials, Beijing 100027, P. R. China

${ }^{2}$ The Quartermaster Equipment Institute of GLD of PLA, Beijing 100010, P. R. China

${ }^{3}$ Key Laboratory Industrial Fermentation Microbiology, University of Science \& Technology, Tianjin 300457, P. R. China

${ }^{4}$ Department of Endocrinology, Chinese PLA General Hospital, Beijing 100853, P. R. China

\begin{abstract}
This paper is concerned with optimization of submerged culture conditions for mycelial growth and Exopolysaccharides (EPS) yield with Coriolus versiolor by both one-factor-at-a-time and orthogonal matrix methods. Glucose and yeast-Extracts were identified to be the most suitable carbon and nitrogen sources, respectively. The optimal initial pH, inoculum size and liquid volume for mycelial growth and EPS yield were $5.0,8 \%$ and $150 \mathrm{~mL} / 500 \mathrm{~mL}$, respectively. Subsequently, the concentration of glucose, yeast-extract, $\mathrm{KH}_{2} \mathrm{PO}_{4}$, and $\mathrm{MgSO}_{4} \cdot 7 \mathrm{H}_{2} \mathrm{O}$ were optimized using the orthogonal matrix method. The effects of media composition on the mycelial growth of Coriolus versiolor were in the order of glucose $>\mathrm{KH} 2 \mathrm{PO} 4>$ yeast-extract $>\mathrm{MgSO} 4 \cdot 7 \mathrm{H} 2 \mathrm{O}$, and those on EPS yield were in the order of glucose $>\mathrm{MgSO}_{4} \cdot 7 \mathrm{H}_{2} \mathrm{O}>$ yeast-extract $>\mathrm{KH}_{2} \mathrm{PO}_{4}$. The optimal concentrations for enhanced yield were determined as $30 \mathrm{~g} / \mathrm{L}$ glucose, $7.0 \mathrm{~g} / \mathrm{L}$ yeast-extract, $1.0 \mathrm{~g} / \mathrm{L} \mathrm{KH_{2 }} \mathrm{PO}, 1.0 \mathrm{~g} / \mathrm{L} \mathrm{MgSO} \cdot 7 \mathrm{H}_{2} \mathrm{O}$, and $40 \mathrm{~g} / \mathrm{L}$ glucose, $6.0 \mathrm{~g} / \mathrm{L}$ yeast-extract, $1.0 \mathrm{~g} / \mathrm{L}$ $\mathrm{KH}_{2} \mathrm{PO}_{4}, 1.5 \mathrm{~g} / \mathrm{L} \mathrm{MgSO} 4 \cdot 7 \mathrm{H} 2 \mathrm{O}$ for mycelial and EPS yield, respectively. The verification experiments confirmed the final medium. This optimization strategy $\left(30 \mathrm{~g} / \mathrm{L}\right.$ glucose, $7.0 \mathrm{~g} / \mathrm{L}$ yeast-extract, $2.0 \mathrm{~g} / \mathrm{L} \mathrm{KH}_{2} \mathrm{PO}_{4}$ and $\left.0.5 \mathrm{~g} / \mathrm{L} \mathrm{MgSO} \cdot 7 \mathrm{H}_{2} \mathrm{O}\right)$ in shake flask culture lead to a mycelial yield of $5.18 \mathrm{~g} / \mathrm{L}$, and EPS yield of $0.64 \mathrm{~g} / \mathrm{L}$, respectively, which were considerably higher than those obtained in preliminary studies. Under optimal culture conditions, the maximum EPS concentration in a 5 - $\mathrm{L}$ stirred-tank bioreactor was $0.75 \mathrm{~g} / \mathrm{L}$, while the maximum mycelial yield was $8.55 \mathrm{~g} / \mathrm{L}$. This also corresponded to $14.67 \%$ and $39.42 \%$ enhancement in EPS yield and mycelial dry weight, respectively, compared with the verification test results.
\end{abstract}

Keywords: Coriolus versiolor; Exopolysaccharide; Mycelial; Submerged culture; Optimization

\section{Introduction}

Coriolus versiolor (CV), known as Yunzhi in China, is a mushroom belonging to species of the Basidiomycetes class of fungi, and its polysaccharide has been widely used as a magic drug to treat cancer and immune deficiency related illnesses [1]. Coriolus versicolor was recorded in the Compendium of Materia Medica by Li Shizhen during the Ming Dynasty in China, as being beneficial to health and able to bring longevity if consumed regularly [2].

However, it is time-consuming to harvest the fruiting body from cultivated mushrooms for commercial purposes [3]. Submerged culture has a number of advantages including higher mycelial yield in a more compact space and shorter time, with fewer chances of contamination [4,5-7], therefore it is now attracting attention as an alternative for efficient yield of mycelia and polysaccharide. In addition to polysaccharide obtain from the biomass, mycelial cultures also excrete EPS into the fermentation broth.

EPS is easier to obtain from submerged culture than the internal polysaccharide localized within the mycelia, but exhibits similar biological activities [8]. In other species, mycelial growth rate, EPS yield rate, and EPS productivity have been shown to vary with environmental conditions and medium composition, including carbon source, nitrogen source, $\mathrm{pH}$, etc. [9].

Medium optimization by the one-factor-at-a-time method involves changing one independent variable (i.e. nutrient, $\mathrm{pH}$, inoculum size, etc.) while fixing the others at certain levels. This single-dimensional search is laborious and time-consuming, especially for a large number of variables, and frequently does not guarantee the determination of optimal conditions. Hence, as a more practical method, the orthogo- nal matrix method was employed to study the relationships between the medium components and their effects on mycelial growth and EPS yield.

The purpose of this study was to optimize the submerged culture conditions to simultaneously produce mycelial biomass and EPS by $\mathrm{Co}$ riolus versiolor using a statistically based experimental design. In the first step, the one-factor-at-a-time method was used to investigate the effects of variables of medium composition (i.e. carbon, and nitrogen) and environmental factors (i.e. $\mathrm{pH}$ and inoculum size) on mycelial growth and EPS yield. Subsequently, the concentration of the medium components was optimized using an orthogonal matrix method.

\section{Materials and Methods}

\section{Microorganism and culture conditions}

Coriolus versiolor was kindly provided by the Quartermaster Equipment Institute of the General Logistics Department, China. The strain was maintained on Potato Dextrose Agar (PDA) at $4^{\circ} \mathrm{C}$ and subcultured every 3 months.

*Corresponding author: Jianchun Zhang, The Research Center of China Hemp Materials,Beijing 100027,China, Tel: + 86-10-65250502; E-mail: jianchunzhang502@263.net

Received April 09, 2012; Accepted June 04, 2012; Published June 06, 2012

Citation: Wang F, Zhang J, Hao L, Jia S, Ba J, et al. (2012) Optimization of Submerged Culture Conditions for Mycelial Growth and Extracellula Polysaccharide Production by Coriolus versiolor. J Bioprocess Biotech 2:124 doi: 10.4172/2155-9821.1000124

Copyright: (c) 2012 Wang F, et al. This is an open-access article distributed unde the terms of the Creative Commons Attribution License, which permits unrestricted use, distribution, and reproduction in any medium, provided the original author and source are credited. 
Cultivation was performed in two stages. The seed culture medium was consisted of the following components: $30.0 \mathrm{~g} / \mathrm{L}$ glucose, $4.0 \mathrm{~g} / \mathrm{L}$ peptone, $1.0 \mathrm{~g} / \mathrm{L} \mathrm{KH}_{2} \mathrm{PO}_{4}$ and $0.5 \mathrm{~g} / \mathrm{L} \mathrm{MgSO}_{4} \cdot 7 \mathrm{H}_{2} \mathrm{O}$. The initial $\mathrm{pH}$ was not adjusted ( $\mathrm{pH} 5.0-5.5)$. The solution was sterilized at $121^{\circ} \mathrm{C}$ for 15 min. The preculture which was inoculated with $3 \sim 4 \mathrm{~cm}^{2}$ mycelium was incubated on a rotary shaker at $160 \mathrm{r} / \mathrm{min}$ and $27^{\circ} \mathrm{C}$ for 6 days. The flask culture experiments were performed in $500 \mathrm{~mL}$ flasks containing 150 $\mathrm{mL}$ of fermentation medium, which was inoculated with $10 \%(v / v)$ of the seed culture. The flasks were cultured under the same conditions as above.

\section{Analysis of mycelial yield and EPS yield}

The biomass was obtained by vacuum filtration, washed twice with distilled water and then dried overnight to a constant weight at $60^{\circ} \mathrm{C}$. EPS was precipitated from the remaining filtrate by mixing $5 \mathrm{~mL}$ with three volumes of $95 \%(\mathrm{v} / \mathrm{v})$ ethanol. It was standing at $4^{\circ} \mathrm{C}$ overnight to precipitate crude EPS. The precipitated EPS was collected by centrifugation at $15,000 \times \mathrm{g}$ for $40 \mathrm{~min}$ at $4^{\circ} \mathrm{C}$ and the supernatant was discarded. The precipitate was then resuspended in an equal volume of $75 \%$ ethanol $[10,11]$ to remove oligosaccharides and centrifuged again as above. The precipitate of EPS was dried at $40^{\circ} \mathrm{C}$ to remove residual ethanol. The EPS content was determined by a phenol-sulfuric acid method using glucose as standard [12].

\section{One-factor-at-a-time}

In each experiment, one factor was varied, while all other factors were holding constant. Different carbon sources (glucose, sucrose, maltose, lactose, malt extract (ME), corn starch (CS)), nitrogen sources (ammonium chloride (AC), ammonium sulfate (AS), potassium nitrate $(\mathrm{PN})$, peptone $(\mathrm{PT})$, yeast-extract $(\mathrm{YE}))$, at different concentrations, major components, and different conditions $(\mathrm{pH}$, inoculum size, liquid volume) were initially studied by single factor experiments.

\section{Orthogonal matrix method}

To investigate the relationships between variables of medium components and optimize their concentrations for mycelial growth and EPS yield, the orthogonal matrix experimental design $\mathrm{L}_{9}\left(3^{4}\right)$ method can be used. According to preliminary experiments, with only $9 \times 2$ replicates (=18) experiments of $\mathrm{L}_{9}\left(3^{4}\right)$ orthogonal projects, three varied levels of each factor were selected, as shown in Table 1.

\section{Results and Discussion}

\section{One-factor-at-a-time}

Screening of carbon sources and its concentrations: Carbohydrates are a major component of the cytoskeleton and they are an important nutritional requirement for growth and development of higher fungi [13]. All of the selected carbon sources resulted in high mycelial growth and product yield. The mycelial dry weight and EPS yield in ME and CS medium which contained complex polysaccharides were higher than those in other carbon sources ( shown in Figure 1a). However,

\begin{tabular}{|c|c|c|c|c|}
\hline Level & $\begin{array}{c}\text { Glucose } \\
\mathrm{A}(\mathrm{g} / \mathrm{L})\end{array}$ & $\begin{array}{c}\text { Yeast-extract } \\
\mathrm{B}(\mathrm{g} / \mathrm{L})\end{array}$ & $\begin{array}{c}\mathrm{KH}_{2} \mathrm{PO}_{4} \\
\mathrm{C}(\mathrm{g} / \mathrm{L})\end{array}$ & $\begin{array}{c}\mathrm{MgSO}_{4} \cdot 7 \mathrm{H}_{2} \mathrm{O} \\
\mathrm{D}(\mathrm{g} / \mathrm{L})\end{array}$ \\
\hline 1 & 20 & 5 & 1 & 0.5 \\
\hline 2 & 30 & 6 & 2 & 1 \\
\hline 3 & 40 & 7 & 3 & 1.5 \\
\hline
\end{tabular}

Symbols A, B, C, and D represent factors of glucose, yeast-powder, $\mathrm{KH} 2 \mathrm{PO} 4$ and $\mathrm{MgSO} 4 \cdot 7 \mathrm{H} 2 \mathrm{O}$, respectively. Symbols 1,2 , and 3 represent concentration levels of each factor.

Table 1: Experimental factors and their levels for orthogonal projects glucose was low priced and biologically was the most effective energy source, so glucose was chosen as the carbon source for analyzing easily of the EPS from Coriolus versiolor.

It can be seen (Figure 1b) that the maximum concentration of 4.10 $\mathrm{g} / \mathrm{L}$ for mycelia yield was achieved with $3 \%$ glucose concentration. However, EPS increased with the increase of glucose concentration which maybe resulted from residual sugar not cleaned completely by alcohol precipitation.

\section{Screening of nitrogen sources and its concentrations}

The effect of nitrogen sources on secondary metabolism is conditioned by many factors [14], including the producing organism, the type and concentration of the nitrogen sources and culture method (stationary or submerged).

Coriolus versiolor could grow on a number of different nitrogen sources, but the nitrogen sources effects on EPS and biomass yield were quite distinct (Figure 2a). Among the five different nitrogen sources examined, yeast-extract was the most effective for enhancing the EPS yield $(0.40 \mathrm{~g} / \mathrm{L})$ and biomass $(4.43 \mathrm{~g} / \mathrm{L})$ by Coriolus versiolor. Inorganic nitrogen was not effective for both EPS and biomass production. Yeastextract has often been used to provide necessary growth factors; however, too high a concentration of yeast extract would lower the use of other carbon sources and cause the reduction of metabolites (Figure $2 \mathrm{~b})$. Besides carbon and nitrogen sources, many growth factors also have positive impact on the yields of EPS such as sodium carboxymethylcellulose, L-glutamic acid, VB1, naphthalene acetic acid, oleic acid, and Tween 80 , which has been proved by one-factor-at-a-time and the orthogonal matrix method [15].

It can be determined that the optimal conditions is $\mathrm{pH} 5.0,8 \%$ of the inoculum size and $150 \mathrm{~mL} / 500 \mathrm{~mL}$ of liquid volume( Figure 3 ).

\section{Orthogonal matrix design to determine the optimum me- dium}

The experimental conditions for each project are listed in Table 2 , and experimental results are included in the last two columns.

\section{Order of effects of factors}

According to the magnitude order of R (Max Dif), the order of effects of all factors on mycelial growth and EPS yield could be determined. The order of effects of factors on mycelial growth was glucose $>\mathrm{KH}_{2} \mathrm{PO}_{4}>$ yeast-extract $>\mathrm{MgSO}_{4} \cdot 7 \mathrm{H}_{2} \mathrm{O}$. Applying the same method, the order of effects of factors on EPS yield was glucose $>\mathrm{MgSO}_{4} \cdot 7 \mathrm{H}_{2} \mathrm{O}$ $>$ yeast-extract $>\mathrm{KH}_{2} \mathrm{PO}_{4}$. This result pointed out that the effect of glucose was more important than that of other nutrients.

\section{Optimum levels of each factor}

To obtain the optimization levels or composition of each factor, the intuitive analysis based on statistical calculation using the data in Table 2 , is shown in Table 3. The results were as follows: (1) to obtain a high mycelial growth, the optimum composition was $30 \mathrm{~g} / \mathrm{L}$ glucose, $7.0 \mathrm{~g} / \mathrm{L}$ yeast-extract, $2 \mathrm{~g} / \mathrm{L} \mathrm{KH}_{2} \mathrm{PO}_{4}$ and $.0 .5 \mathrm{~g} / \mathrm{L} \mathrm{MgSO}_{4} \cdot 7 \mathrm{H}_{2} \mathrm{O}$; (2) to obtain a high EPS yield, the optimum composition was $40 \mathrm{~g} / \mathrm{L}$ glucose, $7.0 \mathrm{~g} / \mathrm{L}$ yeast-extract, $1.0 \mathrm{~g} / \mathrm{L} \mathrm{KH}_{2} \mathrm{PO}_{4}$ and $1.5 \mathrm{~g} / \mathrm{L} \mathrm{MgSO}_{4} \cdot 7 \mathrm{H}_{2} \mathrm{O}$.

\section{Verification Test}

Further experiments were carried out using these nutrient concentrations due to the different results between the one-factor-at-a-time and the orthogonal matrix methods. Finally, the medium composition 
(a)

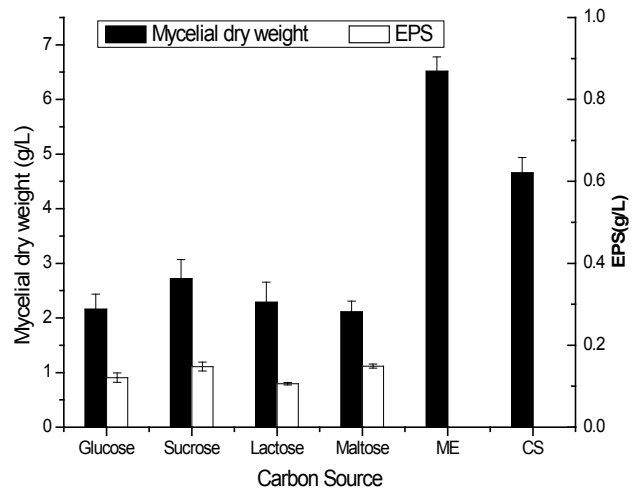

(b)

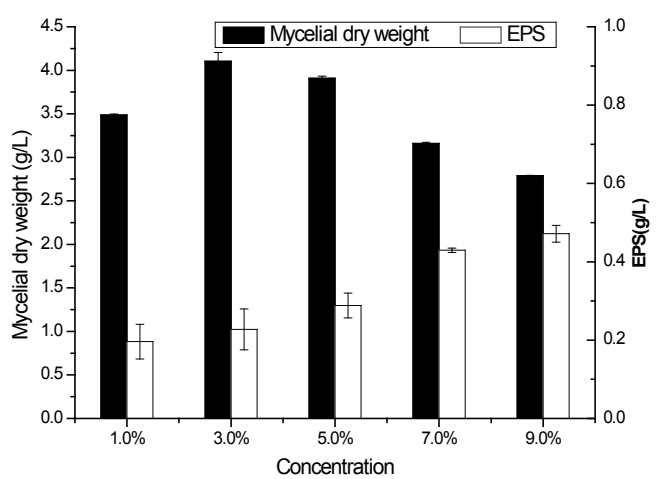

Figure 1: Effect of carbon sources (a) and glucose concentration (b) on mycelial dry weight and EPS yield by Coriolus versiolor

(a)

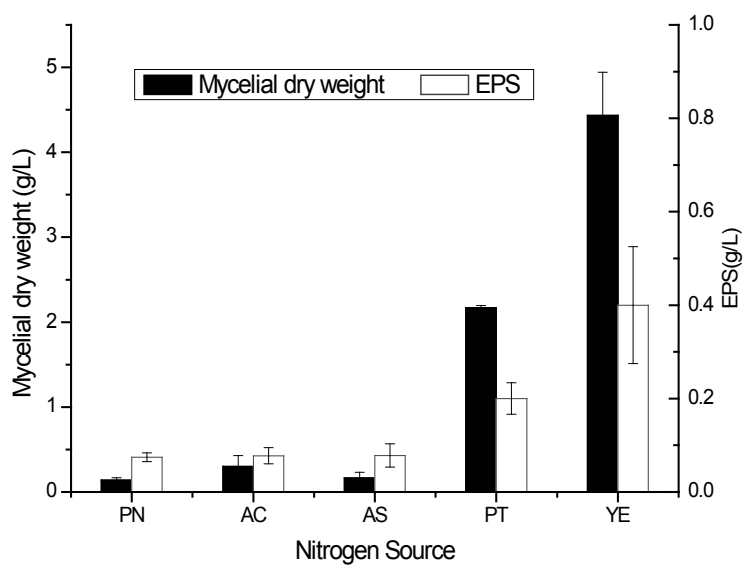

(b)

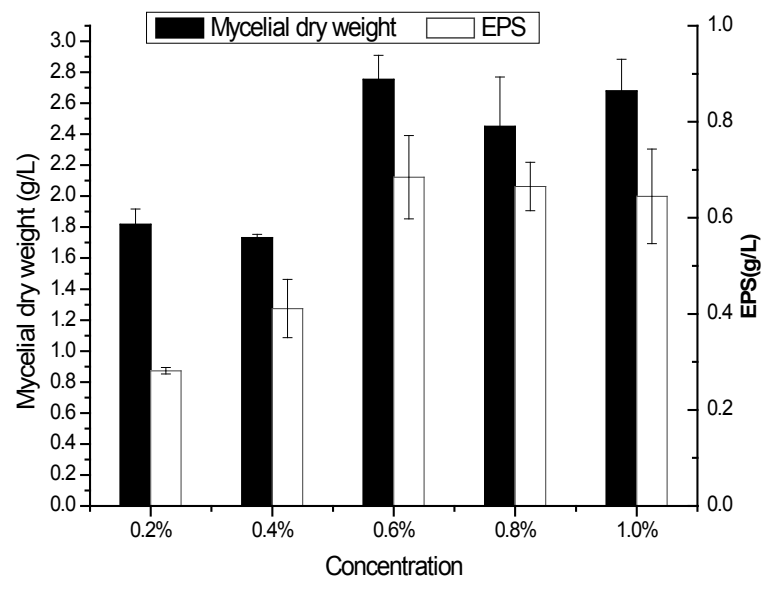

Figure 2: Effect of nitrogen sources (a) and yeast-extract concentration (b) on the mycelial dry weight and EPS yield by Coriolus versiolor

\section{Effects of different fermentation conditions}

(a)

(b)

(c)
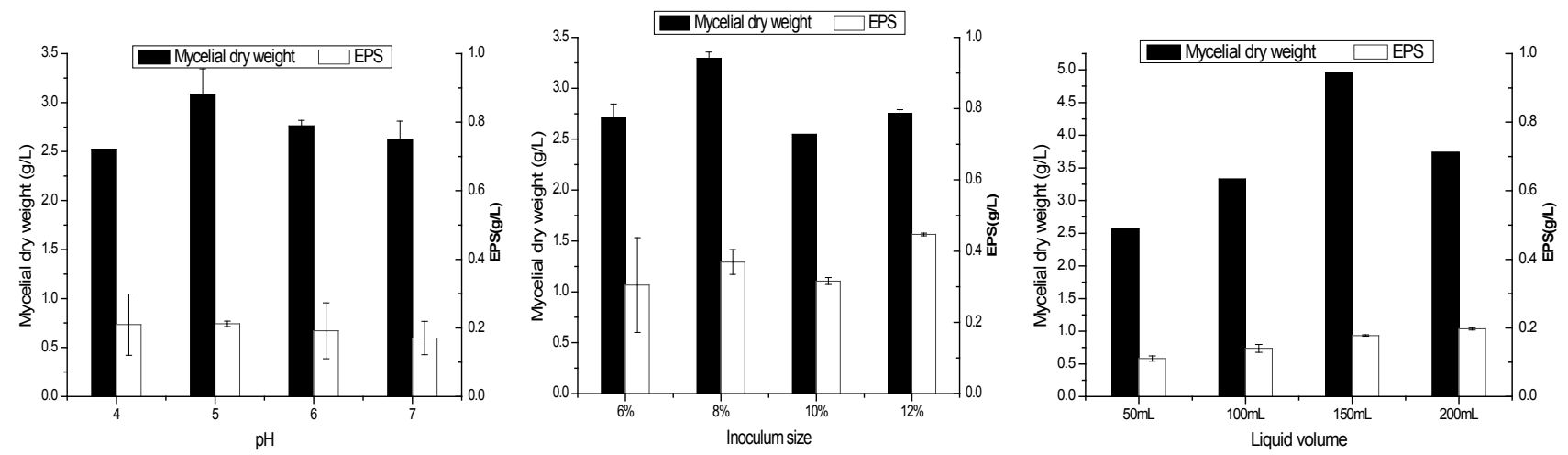

Figure 3: Effect of $\mathrm{pH}(\mathrm{a})$, inoculum size(b), liquid volume(c) on the mycelial dry weight and EPS yield by Coriolus versiolor. 


\begin{tabular}{|c|c|c|c|c|c|c|}
\hline \multirow[t]{2}{*}{ Run } & \multicolumn{5}{|c|}{ Experimental factor } & \multirow{2}{*}{$\begin{array}{c}\text { Result } \\
\text { EPS (g/L) }\end{array}$} \\
\hline & $\begin{array}{c}\text { A } \\
\text { Glucose (g/L) }\end{array}$ & $\begin{array}{c}\text { B } \\
\text { Yeast-extract (g/L) }\end{array}$ & $\frac{\mathrm{C}}{\mathrm{KH}_{2} \mathrm{PO}_{4}(\mathrm{~g} / \mathrm{L})}$ & $\frac{\text { D }}{\mathrm{MgSO}_{4} \cdot 7 \mathrm{H}_{2} \mathrm{O}(\mathrm{g} / \mathrm{L})}$ & Mycelia (g/L) & \\
\hline 1 & $1(20)$ & $1(5)$ & $1(1)$ & $1(0.5)$ & 5.25 & 0.71 \\
\hline 2 & 1 & $2(6)$ & $2(2)$ & $2(1)$ & 5.30 & 0.65 \\
\hline 3 & 1 & $3(7)$ & $3(3)$ & $3(1.5)$ & 5.24 & 0.75 \\
\hline 4 & $2(30)$ & 1 & 2 & 3 & 6.06 & 0.67 \\
\hline 5 & 2 & 2 & 3 & 1 & 5.77 & 0.74 \\
\hline 6 & 2 & 3 & 1 & 2 & 6.15 & 0.70 \\
\hline 7 & $3(40)$ & 1 & 3 & 2 & 5.39 & 0.74 \\
\hline 8 & 3 & 2 & 1 & 3 & 5.41 & 0.87 \\
\hline 9 & 3 & 3 & 2 & 1 & 5.88 & 0.84 \\
\hline
\end{tabular}

The arrangements of column A, B, C, and D were decided by orthogonal design for 4 (factor) $\times 9$ (run number).

Table 2: Application of $\mathrm{L}_{9}\left(3^{4}\right)$ orthogonal projects to the mycelial growth and EPS yield by Coriolus versiolor

\begin{tabular}{|c|c|c|c|c|c|c|c|c|}
\hline & \multicolumn{4}{|c|}{ EPS(g/L) } & \multicolumn{4}{|c|}{ Mycelia(g/L) } \\
\hline & A & B & C & D & A & B & C & D \\
\hline K1 & 0.703 & 0.703 & 0.760 & 0.761 & 5.265 & 5.567 & 5.602 & 5.635 \\
\hline $\mathrm{K} 2$ & 0.704 & 0.756 & 0.720 & 0.697 & 5.992 & 5.494 & 5.746 & 5.613 \\
\hline K3 & 0.814 & 0.763 & 0.742 & 0.763 & 5.559 & 5.756 & 5.468 & 5.568 \\
\hline $\mathrm{k}_{1}$ & 0.234 & 0.234 & 0.253 & 0.254 & 1.755 & 1.856 & 1.867 & 1.878 \\
\hline $\mathrm{k}_{2}$ & 0.235 & 0.252 & 0.24 & 0.232 & 1.997 & 1.831 & 1.915 & 1.871 \\
\hline $\mathrm{k}_{3}$ & 0.271 & 0.254 & 0.247 & 0.254 & 1.853 & 1.919 & 1.823 & 1.856 \\
\hline $\mathrm{R}$ & 0.111 & 0.060 & 0.040 & 0.066 & 0.727 & 0.262 & 0.278 & 0.067 \\
\hline Optimal level & 3 & 3 & 1 & 3 & 2 & 3 & 2 & 1 \\
\hline
\end{tabular}

$K_{i}^{A}=\sum$ mycelial yield at $\mathrm{Ai} ; k_{i}^{A}=K_{i}^{A} / 3 ; R_{i}^{A}=\max \left\{k_{i}^{A}\right\}-\min \left\{k_{i}^{A}\right\}$

Table 3: The range analysis of L9(34) orthogonal experiment of EPS yield

of $30 \mathrm{~g} / \mathrm{L}$ glucose, $7.0 \mathrm{~g} / \mathrm{L}$ yeast-extract, $2.0 \mathrm{~g} / \mathrm{L} \mathrm{KH}_{2} \mathrm{PO}_{4}$ and $0.5 \mathrm{~g} / \mathrm{L}$ $\mathrm{MgSO}_{4} \cdot 7 \mathrm{H}_{2} \mathrm{O}$ was chosen as the optimum formula to obtain the maximum EPS $(0.64 \mathrm{~g} / \mathrm{L})$ while the mycelia dry weight is $5.18 \mathrm{~g} / \mathrm{L}$, which increased by 2.6 times and 1.6 times than those of previous report $(0.18 \mathrm{~g} / \mathrm{L}$ EPS and $2.01 \mathrm{~g} / \mathrm{L}$ biomass) [16], respectively.

\section{The verification experiment result applying in 5-L bioreactor}

Figure 4 showed the typical time courses of mycelial growth and EPS yield in a 5-L stirred-tank bioreactor under optimal culture condition $\left(30 \mathrm{~g} / \mathrm{L}\right.$ glucose, $7.0 \mathrm{~g} / \mathrm{L}$ yeast-extract, $2.0 \mathrm{~g} / \mathrm{L} \mathrm{KH}_{2} \mathrm{PO}_{4}$ and $0.5 \mathrm{~g} / \mathrm{L}$ $\mathrm{MgSO}_{4} \cdot 7 \mathrm{H}_{2} \mathrm{O}$ ) for EPS yield. The maximum EPS yield was achieved at $0.75 \mathrm{~g} / \mathrm{L}$ after $6 \mathrm{~d}$ of fermentation, while the maximum mycelial yield was $8.55 \mathrm{~g} / \mathrm{L}$ after $4 \mathrm{~d}$. This also corresponded to $14.67 \%$ and $39.42 \%$ enhancement in EPS yield and mycelial dry weight, respectively, compared with the verification test results. The result implied that the selected conditions were the most suitable in practice. The variance in $\mathrm{pH}$ value during fermentation was not so significant. Optimization of operating parameter (e.g. agitation, aeration, and dissolved oxygen tension) in bioreactor fermentation deserves further investigation.

Although some research has found no relationship between the mycelial growth and EPS yield, other results have shown a positive correlation between them $[17,18]$. In this experiment, the data indicated the EPS began to accumulate rapidly after the biomass reached the maxima. The relationship between the mycelial and EPS yield is still unclear and is worthy of further study.

Both natural medium and semisynthetic medium contain complex sugar components which have an influence on the estimation for exopolysaccharide secreted by Coriolus versiolor. Thus we chose glucose as the sole carbon source out of consideration for analysis of the fermentation broth even though the yields were less than those of using natural medium [19].
It is not enough convincing only depending on one-factor-at-a-time and orthogonal matrix methods to determine the optimal medium for yield of EPS from Coriolus versiolor. Subsequent experiments can be combined a Box-Behnken design and response surface methodology which has been proved that the yields can be enhanced efficiently [20].

\section{Conclusions}

Coriolus versicolor polysaccharide has been widely studied as a medicinal fungus because of its anti-tumor, antioxidant and immunity improving activities. Most of studies focused on its Intracellular Polysaccharide (IPS), however we hope to improve the yield of EPS which also has various of functions such as antioxidant activity [16].

At first, one-factor-at-a-time was taken. Although it was tedious, defective and ignored in much research, this method was helpful in the selection of factor level in orthogonal matrix design. We then selected the main factors and found the preliminary vicinity of the optimums. Finally the optimal medium was obtained by the verification test. This optimized conditions ( $30 \mathrm{~g} / \mathrm{L}$ glucose, $7.0 \mathrm{~g} / \mathrm{L}$ yeast-extract, $2.0 \mathrm{~g} / \mathrm{L} \mathrm{KH}$ ${ }_{2} \mathrm{PO}_{4}$ and $\left.0.5 \mathrm{~g} / \mathrm{L} \mathrm{MgSO}_{4} \cdot 7 \mathrm{H}_{2} \mathrm{O}\right)$ in shake flask culture led to a mycelial yield of $5.18 \mathrm{~g} / \mathrm{L}$ and EPS yield of $0.64 \mathrm{~g} / \mathrm{L}$, respectively, which increased by 1.6 times and 2.6 times than those of previous report [16], respectively.. The subsequent experiments in 5-L fermentor confirmed the results which obtained the maximum EPS of $0.75 \mathrm{~g} / \mathrm{L}$ and mycelia yield of $8.55 \mathrm{~g} / \mathrm{L}$. This also corresponded to $14.67 \%$ and $39.42 \%$ enhancement in EPS and mycelial yield, respectively, compared with the verification test results.

Two optimization techniques used in this work can be widely applied to other processes for optimization of submerged culture conditions for the mushrooms. The results obtained in this study may be useful for a highly effective yield of biomass and valuable bioactive metabolites. 
Citation: Wang F, Zhang J, Hao L, Jia S, Ba J, et al. (2012) Optimization of Submerged Culture Conditions for Mycelial Growth and Extracellular Polysaccharide Production by Coriolus versiolor. J Bioprocess Biotech 2:124 doi: 10.4172/2155-9821.1000124

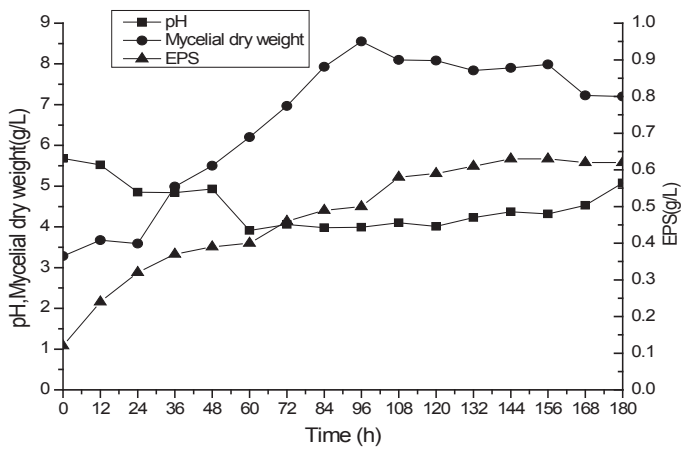

Figure 4: Typical time courses of the mycelial growth and EPS yield by Coriolus versiolor under optimal condition $(30 \mathrm{~g} / \mathrm{L}$ glucose, $7.0 \mathrm{~g} / \mathrm{L}$ yeast-extract, $2.0 \mathrm{~g} / \mathrm{L}$ $\mathrm{KH}_{2} \mathrm{PO}_{4}$ and $0.5 \mathrm{~g} / \mathrm{L} \mathrm{MgSO}_{4} \cdot 7 \mathrm{H}_{2} \mathrm{O}$ ) in a 5 - $\mathrm{L}$ stirred-tank bioreactor at $27^{\circ} \mathrm{C}$ and $100 \mathrm{r} / \mathrm{min}$ for 8 days.

\section{Acknowledgements}

This work was financially supported by the National Natural Science Foundation of China (Grant No.31171662, No. 21006072). We thank Mr Zhi-cun Sheng for his kindly help in fermentation experiments.

\section{References}

1. Yang Q (1999) History, present status and perspectives of the study of Yun Zhi polysaccharopeptide. Advance research in PSP.

2. Ng TB (1998) A review of research on the protein-bound polysaccharide (polysaccharopeptide, PSP) from the mushroom Coriolus versicolor (basidiomycetes: Polyporaceae). General Pharmacology: The Vascular System 30: $1-4$.

3. Huang HC, Liu YC (2008) Enhancement of polysaccharide production by optimization of culture conditions in shake flask submerged cultivation of Grifola umbellata. Journal of the Chinese Institute of Chemical Engineers 39: 307-311.

4. Pokhrel CP, Ohga S (2007) Submerged culture conditions for mycelial yield and polysaccharides production by Lyophyllum decastes. Food Chemistry 105: 641-646.

5. Yang FC, Huang HC, Yang MJ (2003) The influence of environmental conditions on the mycelial growth of Antrodia cinnamomea in submerged cultures. Enzyme and Microbial Technology 33: 395-402.

6. Shih IL, Chou BW, Chen CC, Wu JY, Hsieh C (2008) Study of mycelial growth and bioactive polysaccharide production in batch and fed-batch culture of Grifola frondosa. Bioresource Technology 99: 785-793.

7. Liu RS, Li DS, Li HM, Tang YJ (2008) Response surface modeling the significance of nitrogen source on the cell growth and Tuber polysaccharides production by submerged cultivation of Chinese truffle Tuber sinense. Process Biochem 43: 868-876.

8. Kim DH, Yang BK, Jeong SC, Park JB, Cho SP et al. (2001) Production of a hypoglycemic, extracellular polysaccharide from the submerged culture of the mushroom, Phellinus linteus. Biotechnology Letters 23: 513-517.

9. Papagianni M (2004) Fungal morphology and metabolite production in submerged mycelial processes. Biotechnology Advances 22: 189-259.

10. Lin ES, Sung SC (2006) Cultivating conditions influence exopolysaccharide production by the edible Basidiomycete Antrodia cinnamomea in submerged culture. International Journal of Food Microbiology 108: 182-187.

11. Lin ES, Chen YH (2007) Factors affecting mycelial biomass and exopolysaccharide production in submerged cultivation of Antrodia cinnamomea using complex media. Bioresource Technology 98: 2511-2517.

12. Dubois M, Gilles KA, Hamilton JK, Rebers PA, Smith F (1956) Colorimetric method for determination of sugars and related substances. Anal Chem 28 : 350-356.

13. Xiao JH, Chen DX, Wan WH, Hu XJ, Qi Y, et al. (2006) Enhanced simultaneous production of mycelia and intracellular polysaccharide in submerged cultivation of Cordyceps jiangxiensis using desirability functions. Process Biochemistry 41: 1887-1893.

14. Xu F, Tao W, Cheng L, Guo L (2006) Strain improvement and optimization of the media of taxol-producing fungus Fusarium maire. Biochemical Engineering Journal 31: 67-73.

15. Hao LM, Xing XH , Li Z, Zhang J, Sun J, et al. (2010) Optimization of Effect Factors for Mycelial Growth and Exopolysaccharide Production Schizophyllum commune. Applied Biochemistry and Biotechnology 160: 621-631.

16. Arteiro JMS, Martins MR, Salvador C, Candeias MF, Karmali A, et al. (2011) Protein-polysaccharides of Trametes versicolor production and biological activities. Medicinal Chemistry Research 21: 937-943.

17. Benkortbi O, Hanini S, Bentahar F (2007) Batch kinetics and modelling of Pleuromutilin production by Pleurotus mutilis. Biochemical Engineering Journal 36: 14-18.

18. Jiao YC, Chen QH, Zhou JS, Zhang HF, Chen HY (2008) Improvement of exo-polysaccharides production and modeling kinetics by Armillaria luteovirens Sacc. in submerged cultivation. LWT-Food Science and Technology 41: 1694-1700.

19. Cui J, Goh KKT, Archer R, Singh H (2007) Characterisation and bioactivity of protein-bound polysaccharides from submerged-culture fermentation of Coriolus versicolor Wr-74 and ATCC-20545 strains. Journal of Industrial Microbiology \& Biotechnology 34: 393-402.

20. Thirunavukkarasu A, Nithya R (2011) Response Surface Optimization of Critical Extraction Parameters for Anthocyanin from Solanum melongena. J Bioprocess Biotechniq 1:1-4. 